\title{
Glioblastoma Multiforme Cancer Stem Cells Express Components of the Renin-Angiotensin System
}

\begin{abstract}
Amy Ruth Bradshaw ${ }^{1}$, Agadha Crisantha Wickremesekera ${ }^{1,2}$, Helen D. Brasch ${ }^{1}$, Alice M. Chibnall', Paul F. Davis', Swee T. Tan ${ }^{1,3 \times t}$ and Tinte Itinteang ${ }^{1+}$

' Gillies McIndoe Research Institute, Wellington, New Zealand, ' 2 Department of Neurosurgery, Wellington Regional Hospital, Wellington, New Zealand, ${ }^{3}$ Wellington Regional Plastic, Maxillofacial and Burns Unit, Hutt Hospital, Wellington, New Zealand
\end{abstract}

OPEN ACCESS

Edited by:

Eberval Figueiredo, Hopsital das Clinicas University of

Sao Paulo, Brazil

Reviewed by:

A. Samy Youssef,

University of Colorado, USA

Alisson R. Teles,

McGill University, Canada Leonardo Welling,

Ponta Grossa State University, Brazil

${ }^{*}$ Correspondence:

Swee T. Tan

swee.tan@gmri.org.nz

tEqual senior authors.

Specialty section:

This article was submitted

to Neurosurgery,

a section of the journal

Frontiers in Surgery

Received: 12 July 2016 Accepted: 05 September 2016 Published: 27 September 2016

Citation:

Bradshaw $A R$, Wickremesekera $A C$, Brasch HD, Chibnall AM, Davis PF,

Tan ST and Itinteang T (2016)

Glioblastoma Multiforme Cancer

Stem Cells Express Components of the Renin-Angiotensin System.

Front. Surg. 3:51.

doi: 10.3389/fsurg.2016.00051
Aim: To investigate the expression of the renin-angiotensin system (RAS) in cancer stem cells (CSCs), we have previously characterized in glioblastoma multiforme (GBM).

Methods: 3,3-Diaminobenzidine (DAB) immunohistochemical $(\mathrm{IHC})$ staining for the stem cell marker, SOX2, and components of the RAS: angiotensin converting enzyme (ACE), (pro)renin receptor (PRR), angiotensin II receptor 1 (ATIIR1), and angiotensin II receptor 2 (ATIIR2) on $4 \mu \mathrm{m}$-thick formalin-fixed paraffin-embedded sections of previously characterized GBM samples in six patients was undertaken. Immunofluorescent (IF) IHC staining was performed to demonstrate expression of GFAP, SOX2, PRR, ACE, ATIIR1, and ATIIR2. The protein expression and the transcriptional activities of the genes encoding for ACE, PRR, ATIIR1, and ATIIR2 were studied using Western blotting (WB) and NanoString gene expression analysis, respectively.

Results: DAB and IF IHC staining demonstrated the expression SOX2 on the GFAP+ GBM CSCs. Cytoplasmic expression of PRR by the GFAP+ CSCs and the endothelium of the microvessels was observed. ACE was expressed on the endothelium of the microvessels only, while nuclear and cytoplasmic expression of ATIIR1 and ATIIR2 was observed on the endothelium of the microvessels and the CSCs. ATIIR1 was expressed on the GFAP+ CSCs cells, and ATIIR2 was expressed by the SOX2+ CSCs. The expression of ACE, PRR, and ATIIR1, but not ATIIR2, was confirmed by WB. NanoString gene analysis demonstrated transcriptional activation of ACE, PRR, and ATIIR1, but not ATIIR2.

Conclusion: This study demonstrated the expression of PRR, ATIIR1, and ATIIR2 by the SOX2 CSC population, and ACE on the endothelium of the microvessels, within GBM. ACE, PRR, and ATIIR1 were expressed at the protein and mRNA levels, with ATIIR2 detectable only by $I H C$ staining. This novel finding suggests that the CSCs may be a novel therapeutic target for GBM by modulation of the RAS.

Keywords: glioblastoma multiforme, cancer, stem cells, renin-angiotensin system 


\section{INTRODUCTION}

Glioblastoma multiforme, a grade IV astrocytoma, contributes to about $50 \%$ of all malignant gliomas $(1,2)$. It almost invariably recurs following surgical resection, radiotherapy, and chemotherapy (3-6). This poor prognosis has been ascribed to the presence of cancer stem cells (CSCs) within GBM, which propagate and differentiate to form downstream cancer cells that make up the bulk of the tumor (7-10).

The CSC concept proposes that a cancer originates from a small population of CSCs, which are generated by upregulation of certain genes in putative resident stem or progenitor cells $(11,12)$. These genetic alterations confer, upon these cells, the capacity to proliferate and differentiate in an uncontrolled manner resulting in tumorigenesis (11-14). CSCs can be identified using markers associated with embryonic stem cells (ESCs) $(15,16)$, including ESC markers such as transcription factors NANOG, SALL4, and OCT4, transcription co-factor SOX2 and signaling molecule pSTAT3 (17-21).

Physiologically, the renin-angiotensin system (RAS) is an endocrine system involving conversion of angiotensinogen (ANG) to angiotensin I (ATI) by renin and then to angiotensin II (ATII) by angiotensin converting enzyme (ACE) (22). Renin and its precursor (pro)renin can also bind to the (pro)renin receptor (PRR) to activate MAPK signaling cascades and synthesis of tissue remodeling proteins such as collagen-1, fibronectin, PAI-1, and TGF $\beta-1$ (23-26). Interestingly, the binding of (pro) renin to the PRR also enables conformational activation of the (pro)renin to renin, thereby suggesting the enzyme-like activity of PRR (27).

It has been proposed that ATIIR1 and ATIIR2 are mutually antagonistic in their actions (28-30). There is evidence indicating that ATIIR1 and ATIIR2 play key roles in determining stem cell lineages $(31,32)$. Inhibition of binding of ATII to either ATIIR1 or ATIIR2 reveals that human hemangioblasts differentiate into either hematopoietic or endothelial progenitor cells depending on whether the signal was transmitted through ATIIR1 or ATIIR2 (31), indicating that the RAS can directly influence stem cell differentiation patterns.

The expression of ANG, (pro)renin, ACE, ATII, ATIIR1, and ATIIR2 has been reported in GBM in humans (33), and components of the RAS may be present on CSCs within this tumor (31, $33,34)$.

We have recently demonstrated the presence of CSCs by their expression of the ESC markers NANOG, OCT4, SALL4, pSTAT3, and SOX2 within the GFAP+ GBM tumor samples (35). The aim of this study was to investigate if components of the RAS, namely PRR, ACE, ATIIR1, and ATIIR2 were expressed by this CSC population within GBM.

\section{MATERIALS AND METHODS}

\section{Tissue Samples}

Six previously characterized GBM tissue samples (35) from 3 male and 3 female patients aged $42-81$ years (mean, 64.2 years) were sourced from the Gillies McIndoe Research Institute Tissue
Bank, for this study, which was approved by the Central Health and Disabilities Ethics Committee (ref. no. 15CEN28).

\section{Histology and Immunohistochemical Staining}

Four micrometer-thick formalin-fixed paraffin-embedded sections of GBM from six patients were used for hematoxylin and eosin (H\&E) staining confirming the presence of GBM by an anatomical pathologist (HDB). Immunohistochemical (IHC) staining was performed on the Leica Bond $\mathrm{Rx}$ autostainer (Leica, Nussloch, Germany) as previously described (36). 3,3-Diaminobenzidine (DAB) IHC staining for SOX2 (1:500; cat\# PA094, Thermo Fisher, Scientific, Scoresby, VIC, Australia), PRR (1:2000; cat\# ab40790, Abcam, Cambridge, UK), ATIIR1 (1:30; cat\# ab9391, Abcam), ATIIR2 (1:2000; cat\# NBP1-77368, Novus Biologicals, LLC, Littleton, CO, USA), ACE (1:100; cat\# MCA2054, AbD Serotec, Kidlington, UK) diluted with Bond ${ }^{\mathrm{TM}}$ primary antibody diluent (cat\# AR9352, Leica) was done for all tissue samples. Immunofluorescent (IF) IHC staining was performed on two representative GBM tissue samples from the original cohort of patients used for DAB IHC staining, using identical primary antibodies and concentrations. Antibodies used for IF IHC detection of PRR and ATIIR2 combinations were Vecta fluor Excel anti-rabbit 594 (ready-to-use; cat\# VEDK-1594, Vector Laboratories, CA, USA) and Alexa Fluor anti-mouse 488 (1:500; cat\#A21202, Life Technologies, Carlsbad, CA, USA). Antibodies for IF IHC staining for ACE and ATIIR1 combinations were Vecta fluor Excel anti-mouse (ready-to-use; cat\# VEDK2488, Vector Laboratories) and Alexa Fluor anti-rabbit 594 (1:500; cat\# A21207, Life Technologies). All IF IHC-stained slides were mounted using Vectashield HardSet antifade mounting medium with DAPI (Vector Laboratories).

Appropriate positive control human tissues for the primary antibodies were placenta for PRR (37), liver for ATIIR1 (38) and ACE (39), kidney for ATIIR2 (38), and skin for SOX2 (35). A secondary and tertiary only negative control was performed on a GBM sample randomly selected from the original cohort of GBM samples used for DAB IHC staining.

\section{Image Analysis}

All DAB IHC stained-slides were visualized with an Olympus BX53 light microscope (Tokyo, Japan) and images were captured with the CellSens 2.0 software (Olympus). IF IHC-stained slides were viewed, and images were captured using an Olympus FV1200 biological confocal laser scanning microscope (Olympus) with images processed using CellSens Dimension 1.11 2D deconvolution algorithm software (Olympus).

\section{Western Blotting}

Five snap-frozen samples of GBM of the original cohort used for DAB IHC staining were washed in $1 \times$ PBS and homogenized in RIPA buffer (cat\# R0278, Sigma-Aldrich, St Lewis, MA, USA) supplemented with Halt ${ }^{\mathrm{TM}}$ Protease and Phosphatase Inhibitor Cocktail (cat\# 1861281, Thermo Scientific, Waltham, MA, USA) 
and dithiothreitol (DTT) (cat\# DTT-RO, Sigma-Aldrich, St Lewis, MA, USA). Protein was precipitated using a Calbiochem ${ }^{\circledR}$ ProteoExtract $^{\circledR}$ Protein Precipitation Kit (cat\# 539180, EMD Millipore Corp., Billerice, MA, USA) for $1 \mathrm{~h}$ at $-20^{\circ} \mathrm{C}$, washed and re-suspended in $1 \times$ Laemmli sample buffer (cat\# 161-0737, Bio-Rad, Hercules, CA, USA) with 1\% DTT. Equal amounts of protein were heated at $85^{\circ} \mathrm{C}$ and separated on Bolt ${ }^{\mathrm{TM}} 4-12 \%$ Bis-Tris Plus gels (cat\# NW04120BOX, Invitrogen, Carlsbad, CA, USA) via electrophoresis. Separated protein was transferred to a nitrocellulose membrane (cat\# IB23001, Life Technologies, Carlsbad, CA, USA) and blocked in $1 \times$ TBST containing $2 \%$ skim milk powder for $90 \mathrm{~min}$ at $4^{\circ} \mathrm{C}$. Primary antibody probing for each RAS marker was overnight in TBST at $4^{\circ} \mathrm{C}$ with the following primary antibodies at the given concentrations: PRR (ATP6IP2, 1:500, cat\# ab40790, Abcam, Cambridge, UK), ATIIR1 (AT2R1, 1:500; cat\# sc-1173, Santa Cruz, CA, USA), ATIIR2 (1:5000; cat\# ab92445, Abcam), and ACE (1:200; cat\# sc-12184, Santa Cruz). Secondary antibody probing was in $1 \times$ TBST for $1 \mathrm{~h}$ at $4^{\circ} \mathrm{C}$ with goat anti-rabbit $\operatorname{HRP}(1: 10,000$; cat\# A16110, Thermo Fisher) or donkey anti-goat HRP (1:10,000; cat\# ab97120; Abcam). ACE tertiary cascade used a rabbit anti-goat Superclonal ${ }^{\mathrm{TM}}$ biotin conjugated secondary antibody (1:20,000; cat\# A27013, Thermo Fisher) followed by a Pierce ${ }^{\mathrm{TM}}$ Streptavidin Poly HRP (1:5000, cat\# 21140, Thermo Fisher) at $4^{\circ} \mathrm{C}$ for $10 \mathrm{~min}$. $\beta$-actin antibody probing was performed with the iBind ${ }^{\mathrm{TM}}$ Flex device (cat\# SLF2000, Life Technologies) using primary mouse monoclonal anti- $\beta$-actin (1:2000 cat\# ab8226, Abcam) and secondary donkey anti-mouse Alexa fluor 488 (1:2000; cat\# A21202, Thermo Fisher). Clarity Western ECL (cat\# 1705061, Bio-Rad) was used as the substrate for visualizing HRP detected protein bands, and the Chemi Doc MP Imaging System (Bio-Rad) and Image Lab 5.0 software (Bio-Rad) were used for both HRP and fluorescent band detection and analysis. Appropriate positive controls were human placenta for PRR (37) and ATIIR1 (40), PC3 cell lysate for ATIIR2 (41), and mouse lung for ACE (42). Negative controls were NTERA2 for ATIIR2, HeLa cell lysate for ACE, and no negative tissues or lysates could be found for either the PRR or ATIIR1.

\section{Nanostring Gene Expression Analysis}

Total RNA was extracted from $\sim 20 \mathrm{mg}$ of snap-frozen GBM tissue $(n=6)$ from the same cohort of patients included in DAB IHC staining using the MagJET RNA kit (cat\# k2731, Thermo Scientific) and the Kingfisher Duo RNA extraction machine (Thermo Scientific). All samples were quantitated and quality controlled with the NanoDrop 2000 Spectrophotometer (Thermo Scientific) and the Qubit 2.0 Fluorimeter (Thermo Scientific). The samples with A260/A230 $\geq 1.5$ and A260/ A280 2 were used for further analyses. The integrity of the RNA was assessed by the New Zealand Genomics Ltd. (Dunedin, New Zealand) using Agilent 2100 BioAnalyzer (Agilent Technologies). The isolated RNA was then subjected to NanoString nCounter ${ }^{\mathrm{TM}}$ Gene Expression Assay (NanoString Technologies, Seattle, WA, USA) as completed by New Zealand Genomics Ltd (Dunedin, New Zealand), according to the manufacturer's protocol. Probes for the genes encoding the PRR (NM_005765.2), ATIIR1 (NM_000685.3), ATIIR2 (NM_000686.3), ACE (NM_000789.2) and the housekeeping gene, and GAPDH (NM_002046.3) were designed and synthesized by NanoString Technologies. Raw data were analyzed with Microsoft Excel using standard settings and were normalized against the housekeeping genes.

\section{RESULTS}

\section{3,3-Diaminobenzidine Immunohistochemical Staining}

3,3-Diaminobenzidine IHC staining for SOX2, PRR, ATIIR1, ATIIR2, and ACE was performed on six GBM samples with the diagnosis confirmed by H\&E staining. SOX2 was widely expressed by cells within GBM (Figure 1A, brown). These SOX2+ CSCs, that we have previous identified (35), demonstrated cytoplasmic expression of PRR, which was also expressed on the endothelium of the microvessels (Figure 1B, brown). ACE was expressed on the endothelium of the microvessels only, with minimal staining seen on the CSCs (Figure 1C, brown). Nuclear and cytoplasmic expression of ATIIR1 (Figure 1D, brown) and ATIIR2 (Figure 1E, brown) was observed on the endothelium of the microvessels and the CSCs within GBM.

Expected staining patterns for SOX2 (Image S1A in Supplementary Material, brown), PRR (Image S1B in Supplementary Material, brown), ATIIR1 (Image S1C in Supplementary Material, brown), ATIIR2 (Image S1D in Supplementary Material, brown), and ACE (Image S1E in Supplementary Material, brown) were demonstrated in the respective positive controls. Staining with the omission of the primary antibodies in a GBM sample provided an appropriate negative control (Image S1F in Supplementary Material).

\section{Immunofluorescent Immunohistochemical Staining}

The presence of CSCs within GBM was demonstrated by the relatively abundant expression of the ESC marker SOX2 (Figure 2A, red) on the GFAP+ cells (Figure 2A, green) within GBM, as recently reported (35). We then investigated the expression of PRR (Figure 2B, red) in GBM, by performing IF IHC co-staining with GFAP (Figure 2B, green), which demonstrated that most of the GFAP+ CSCs within GBM expressed PRR. To determine the expression of ACE, we performed dual staining for ACE (Figure 2C, green) and SOX2 (Figure 2C, red) and showed mutually exclusive expression of these markers. Interestingly, ACE was expressed on the endothelial cells with erythrocytes evident within the lumina of the microvessels. We also showed the expression of ATIIR1 (Figure 2D, green) on the SOX2+ (Figure 2D, red) CSC population. ATIIR2 (Figure 2E, red) was expressed on the GFAP+ (Figure 2E, green) CSCs in GBM that were demonstrated to express SOX2 (35). Appropriate negative controls, consisting of omission of the primary antibodies did not reveal any staining (Figure 2F). 

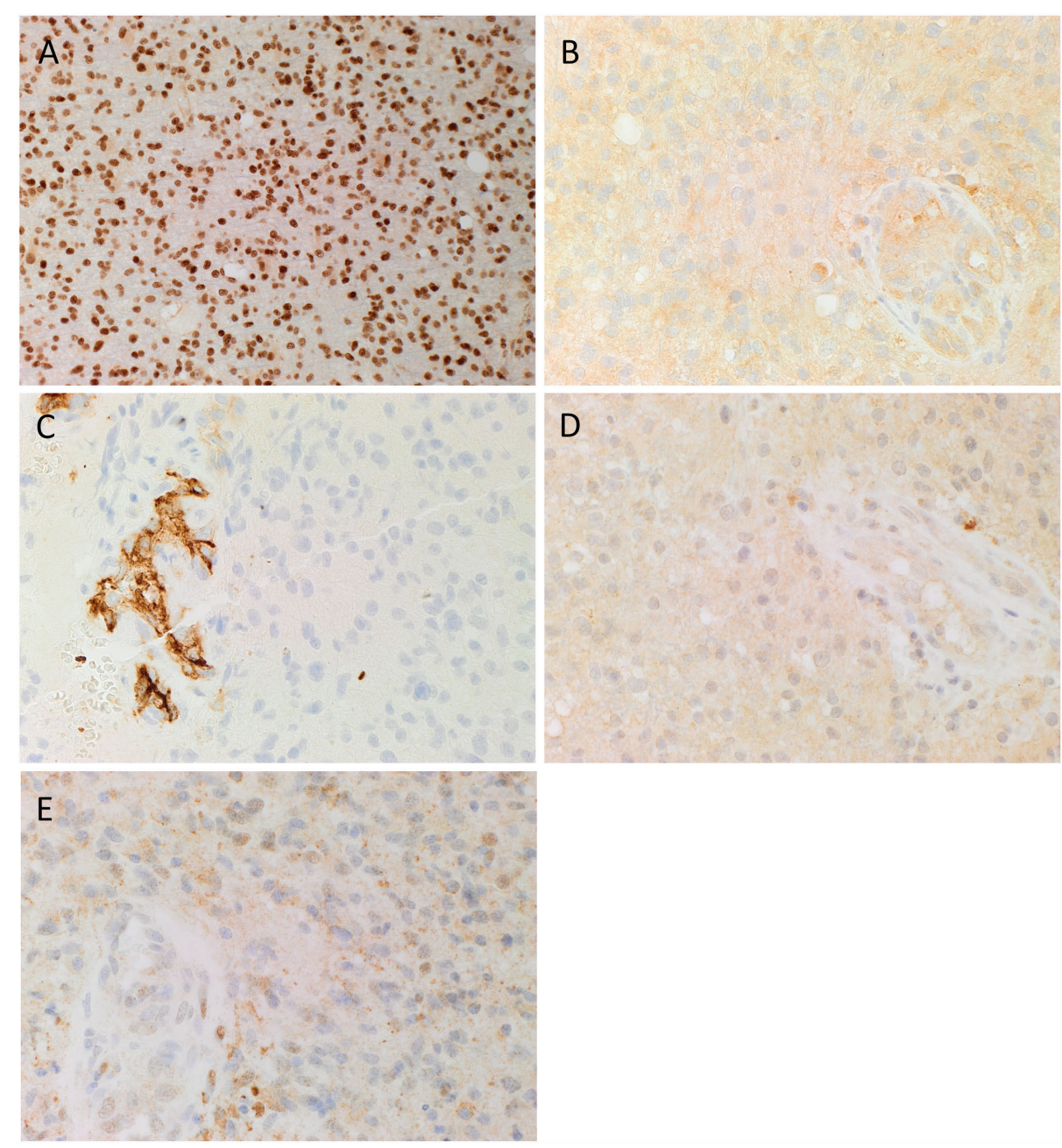

FIGURE 1 | Representative 3,3-diaminobenzidine immunohistochemical stained images demonstrating cytoplasmic expression of SOX2 [(A), brown], PRR [(B), brown] by cells within GBM, and the endothelium of the microvessels. ACE [(C), brown] was present only in the endothelium of the microvessels with no staining of the cells within the tumor. Cytoplasmic and nuclear staining of ATIIR1 [(D), brown] and ATIIR2 [(E), brown] was observed on the cells within the tumor and the endothelium of the microvessels. Cell nuclei were counterstained with hematoxylin [(A-E), blue]. Original magnification: 400x.

\section{Western Blotting}

Western blotting was performed to examine the presence of components of the RAS in GBM samples of five patients included in DAB IHC staining. PRR (Figure 3A) and ATIIR1 (Figure 3B) were present in all five samples with bands of $\sim 37$ and $45 \mathrm{kDa}$, respectively. Bands of $\sim 70 \mathrm{kDa}$ represent PRR dimerization (Figure 3A). ATIIR2 was absent in all five samples (Figure 3C), while ACE was present, at low levels, in all five samples (Figure 3D).

\section{NanoString Analysis}

NanoString analyses demonstrated that PRR and ACE were expressed in GBM samples of all six patients included in DAB IHC staining, while ATIIR1 was present in only two samples, and ATIIR2 was below detectable levels in all six samples examined (Figure 4).

\section{DISCUSSION}

Cancer stem cells have been identified in many cancer types (43-48) and were first characterized in GBM by Singh et al. (8, 49). These findings support the CSC concept of cancer proposing that a tumor originates from a small population of cells imbued with the properties of infinite self-renewal and capacity to differentiate into multiple cellular lineages $(11-13,50)$. Components of the RAS have also been previously identified in GBM (33) and other cancers $(34,51,52)$. Additionally, inhibition of the RAS leads to reduced tumor growth indicating a role for the RAS in cancer progression (53-56). We have recently characterized the CSC population within GBM using the ESC markers pSTAT3, SOX2, SALL4, OCT4, and NANOG and demonstrated their relative expression to the GFAP+ cells within GBM tissues (35). Here, we have shown the expression of PRR, ATIIR1, and ACE within GBM tumors at the protein and mRNA levels. 

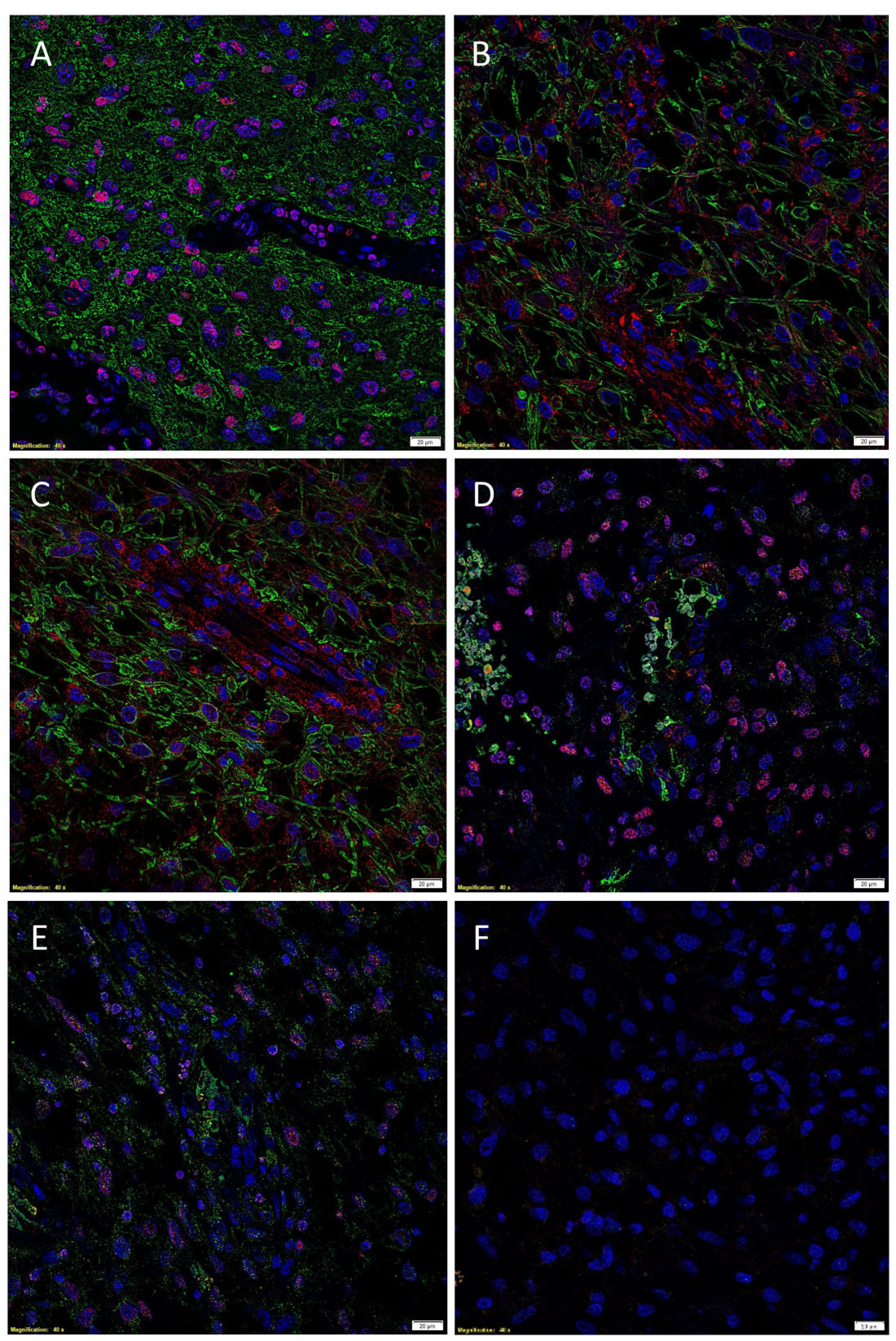

FIGURE 2 | Representative immunofluorescent immunohistochemical stained images demonstrating the expression of SOX2 [(A), red], PRR [(B), red], and ATIIR2 [(C), red] on GFAP+ CSCs [(A-C), green] and expression of ACE [(D), green] and ATIIR1 [(E), green] on SOX2+ CSCs [(D,E), red]. Negative control was a GBM tissue section with omission of the primary antibody (F). Cell nuclei were counterstained with 4', 6'-diamidino-2-phenylindole [(A-F), blue]. Scale bars: $20 \mu \mathrm{m}$.

It is intriguing that DAB and IF IHC staining demonstrated the presence of ATIIR2, but this finding was not confirmed by $\mathrm{WB}$ and NanoString analyses. This may suggest non-specific binding of the antibody used in DAB and IF IHC staining or, potentially, the splice variants we used did not fully cover ATIIR2. This remains a topic of further investigation.

We have shown that components of the RAS were expressed by the CSCs that we have demonstrated to express SOX2 (35). This finding is particularly interesting when considering the proposed non-angiogenic actions of the RAS. Hemangioblasts are derived from ESCs and are capable of differentiating into either endothelial/vascular or hematopoietic stem cells (57) - an ability directly modulated by differential ATII signaling through either of two receptors, namely ATIIR1 and ATIIR2 (31). The expression of ACE on the endothelium of the microvessels within GBM presented in this report may suggest a putative primitive endothelial 
A

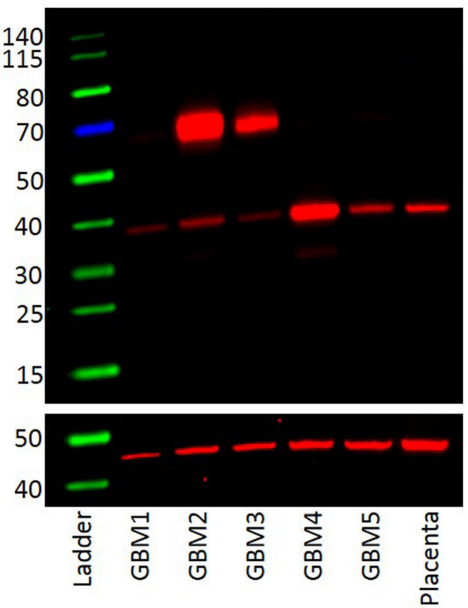

C

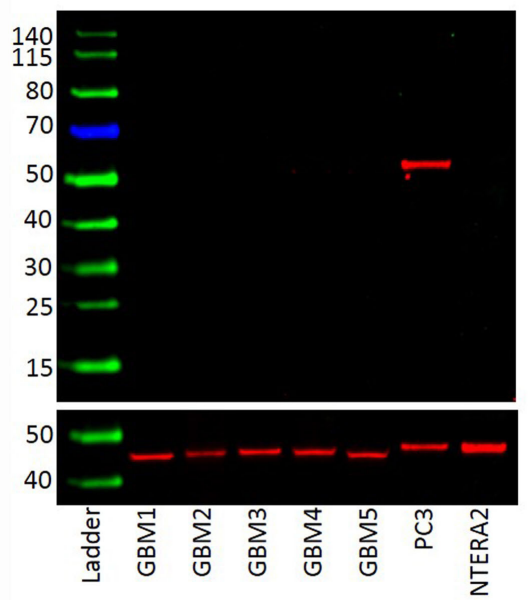

B
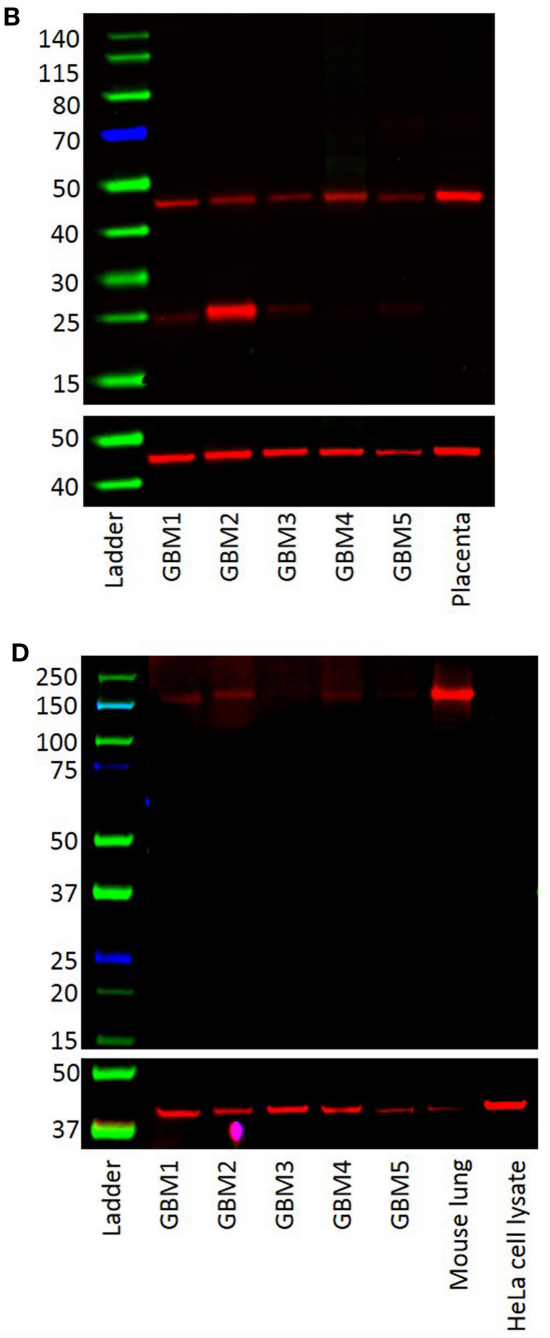

FIGURE 3 | Western blots demonstrating the expression of PRR ( 38 kDa) (A) and ATIIR1 ( 45 kDa) (B) in all five GBM samples. ATIIR2 was not detected in any of the samples (C). ACE was detected in four out of the five GBM samples examined (D).

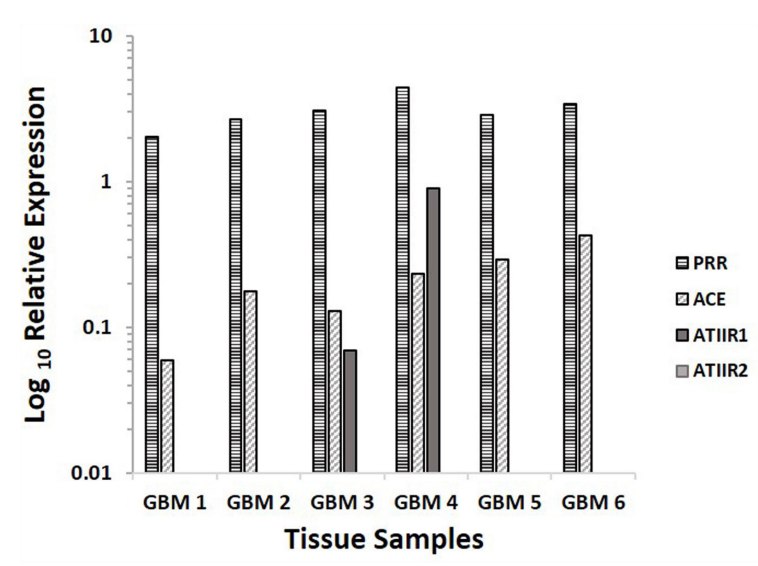

FIGURE 4 | Relative expression of mRNA transcripts of the components of the RAS in six GBM samples, depicted as a ratio over the GUSB housekeeper. PRR and ACE were expressed in all six samples. ATIIR1 was present in two and ATIIR2 was below detectable levels out of the six GBM samples examined. phenotype, similar to the expression seen in hemangioblasts (49), and may possibly account for the vascular mimicry previously reported in GBM (58), although this remains the topic of further investigation.

This report demonstrates that components of the RAS are putatively expressed on CSCs within GBM and may dictate cellular commitment to a particular lineage. We and others have proposed a phenotype of the CSCs, similar to ESCs, in GBM (12, $13,35)$. This investigation confirms previous reports of expression of components of the RAS in GBM (33). However, based on our recent report of the CSCs in GBM (35), it is noteworthy that the putative CSCs in GBM express certain components of the RAS.

In this report, we show abundant expression of the ESC marker SOX2 on the GFAP+ GBM population, denoting a putative CSC phenotype. Furthermore, we demonstrate the expression of PRR, ATIIR1, and ATIIR2 on most of the GFAP+ CSC population within GBM, with ACE being expressed on the endothelium of the microvessels.

Although this is a relatively small study, the results offer novel insights into the role of the RAS in GBM. It is exciting to speculate 
that further studies may lead to CSCs in GBM being identified as a potential therapeutic target by modulating the RAS using existing medications.

\section{ETHICS APPROVAL}

The study was approved by the Central Health and Disabilities Ethics Committee (ref. no. 15CEN28).

\section{AUTHOR CONTRIBUTIONS}

TI and ST formulated the study hypothesis. TI, AW, and STT designed the study. TI, HDB, ARB, AW, PFD, and STT interpreted the DAB IHC data. TI, AW, and STT interpreted the IF IHC data. ARB performed WB analysis. ARB, TI, AW, PFD, and STT interpreted the WB data. AMC processed the tissues for NanoString analysis and interpreted the data. ARB, TI, PFD, AW, and STT drafted the

\section{REFERENCES}

1. Thakkar JP, Dolecek TA, Horbinski C, Ostrom QT, Lightner DD, Barnholtz-Sloan JE, et al. Epidemiologic and molecular prognostic review of glioblastoma. Cancer Epidemiol Biomarkers Prev (2014) 23(10):1985-96. doi:10.1158/1055-9965

2. Ostrom QT, Bauchet L, Davis FG, Deltour I, Fisher JL, Eastman C, et al. The epidemiology of glioma in adults: a "state of the science" review. Neuro Oncol (2014) 16(7):896-913. doi:10.1093/neuonc/nou087

3. Bradshaw A, Wickremsekera A, Tan ST, Peng L, Davis PF, Itinteang T. Cancer stem cell hierachy in glioblastoma multiforme. Front Surg (2016) 3:21. doi:10.3389/fsurg.2016.00021

4. Rulesh AM, Keller J, Klener J, SroubekJ, Dbaly V, Syrucek M, et al. Long-term survival of patients suffering from glioblastoma multiforme treated with tumor-treating fields. World J Surg Oncol (2012) 10:220. doi:10.1186/1477-7819-10-220

5. Weller M, Cloughesy T, Perry JR, Wick W. Standards of care for treatment of recurrent glioblastoma-are we there yet? Neuro Oncol (2013) 15(1):4-27. doi:10.1093/neuonc/nos273

6. Gastrell P, Woodring S, McSherry F, Herndon JE II, Desjardins A, Friedman $\mathrm{H}$, et al. Characterization of late recurrence in long-term survivors of primary glioblastoma. Austin J Clin Neurol (2015) 2(1):1019.

7. Ignatova TN, Kukekov VG, Laywell ED, Suslov ON, Vrionis FD, Steindler DA. Human cortical glial tumors contain neural stem-like cells expressing astroglial and neuronal markers in vitro. Glia (2002) 39(3):193-206. doi:10.1002/ glia.10094

8. Singh SK, Clarke ID, Terasaki M, Bonn VE, Hawkins C, Squire J, et al. Identification of a cancer stem cell in human brain tumors. Cancer Res (2003) 63(18):5821-8.

9. Yuan X, Curtin J, Xiong Y, Liu G, Waschsmann-Hogiu S, Farkas DL, et al. Isolation of cancer stem cells from adult glioblastoma multiforme. Oncogene (2004) 23(58):9392-400. doi:10.1038/sj.onc.1208311

10. Kelly JJ, Stechishin O, Chojnacki A, Lun X, Sun B, Senger DL, et al. Proliferation of human glioblastoma stem cells occurs independently of exogenous mitogens. Stem Cells (2009) 27(8):1722-33. doi:10.1002/stem.98

11. Lapidot T, Sirard C, Vormoor J, Murdoch B, Hoang T, Caceres-Cortes J, et al. A cell initiating human acute myeloid leukaemia after transplantation into SCID mice. Nature (1994) 367(6464):645-8. doi:10.1038/367645a0

12. Rajaraman R. The origin of tumor cell heterogeneity. IUP JBiotechnol (2010) 4(4):7-43.

13. Shipitsin M, Polyak K. The cancer stem cell hypothesis: in search of definitions, markers, and relevance. Lab Invest (2008) 88(5):459-63. doi:10.1038/ labinvest.2008.14 manuscript. All authors commented on and approved the manuscript.

\section{ACKNOWLEDGMENTS}

We thank Ms. Liz Jones and Dr. Jonathan Dunne of the Gillies McIndoe Research Institute for their assistance in IHC staining and advice regarding $\mathrm{WB}$, respectively.

\section{SUPPLEMENTARY MATERIAL}

The Supplementary Material for this article can be found online at http://journal.frontiersin.org/article/10.3389/fsurg.2016.00051

IMAGE S1 | DAB IHC stained images of positive control human samples using placenta for SOX2 [(A), brown] and PRR [(B), brown]; liver for ATIIR1 [(C) and brown]; kidney for ATIIR2 [(D), brown] and ACE [(E), brown]. A GBM tissue section stained in the absence of primary antibody, was used as an appropriate negative control (F). All slides were counterstained with hematoxylin to illustrate cell nuclei (blue). Original magnification: 400x.

14. Khan G, Griffith K, Greenson J, Takebe N, Zalupski M, Simeone D, editors. Cancer stem cells (CSC) and inhibition of hedgehog (Hh) pathway signaling in advanced pancreatic cancer: GDC-0449 in combination with gemcitabine (Gem). Abstract Presented at the American Association for Cancer Research's Pancreatic Cancer: Progress and Challenges Conference. Lake Tahoe, NV (2012).

15. Zhao W, Ji X, Zhang F, Li L, Ma L. Embryonic stem cell markers. Molecules (2012) 17(6):6196-236. doi:10.3390/molecules17066196

16. Schoenhals M, Kassambara A, De Vos J, Hose D, Moreaux J, Klein B. Embryonic stem cell markers expression in cancers. Biochem Biophys Res Commun (2009) 383(2):157-62. doi:10.1016/j.bbrc.2009.02.156

17. Schmitz M, Temme A, Senner V, Ebner R, Schwind S, Stevanovic S, et al. Identification of SOX2 as a novel glioma-associated antigen and potential target for T cell-based immunotherapy. Br J Cancer (2007) 96(8):1293-301. doi:10.1038/sj.bjc.6603802

18. Li W, Wei W, Zhu S, Zhu J, Shi Y, Lin T, et al. Generation of rat and human induced pluripotent stem cells by combining genetic reprogramming and chemical inhibitors. Cell Stem Cell (2009) 4(1):16-9. doi:10.1016/ j.stem.2008.11.014

19. Olmez I, Shen W, McDonald H, Ozpolat B. Dedifferentiation of patient-derived glioblastoma multiforme cell lines results in a cancer stem cell-like state with mitogen-independent growth. J Cell Mol Med (2015) 19(6):1262-72. doi:10.1111/jcmm.12479

20. Zhang L, Yan Y, Jiang Y, Cui Y, Zou Y, Qian J, et al. The expression of SALL4 in patients with gliomas: high level of SALL4 expression is correlated with poor outcome. J Neurooncol (2015) 121(2):261-8. doi:10.1007/s11060-014-1646-4

21. Rahaman SO, Harbor PC, Chernova O, Barnett GH, Vogelbaum MA, Haque SJ. Inhibition of constitutively active Stat 3 suppresses proliferation and induces apoptosis in glioblastoma multiforme cells. Oncogene (2002) 21(55):8404-13. doi:10.1038/sj.onc. 1206047

22. Steckelings U, Unger T. Use of Angiotensin II Agonists. Google Patents (2014).

23. Schroten NF, Gaillard CAJM, van Veldhuisen DJ, Szymanski MK, Hillege HL, de Boer RA. New roles for renin and prorenin in heart failure and cardiorenal crosstalk. Heart Fail Rev (2012) 17(2):191-201. doi:10.1007/ s10741-011-9262-2

24. Huang Y, Wongamorntham S, Kasting J, McQuillan D, Owens R, Yu L, et al. Renin increases mesangial cell transforming growth factor- $\beta 1$ and matrix proteins through receptor-mediated, angiotensin II-independent mechanisms. Kidney Int (2006) 69(1):105-13. doi:10.1038/sj.ki.5000011

25. Huang Y, Noble N, Zhang J, Xu C, Border W. Renin-stimulated TGF- $\beta 1$ expression is regulated by a mitogen-activated protein kinase in mesangial cells. Kidney Int (2007) 72(1):45-52. doi:10.1038/sj.ki.5002243 
26. Huang Y, Border WA, Noble NA. Functional renin receptors in renal mesangial cells. Curr Hypertens Rep (2007) 9(2):133-9. doi:10.1007/s11906-007-0024-4

27. Nguyen G, Muller DN. The biology of the (pro) renin receptor. J Am Soc Nephrol (2010) 21(1):18-23. doi:10.1681/ASN.2009030300

28. Allen A, Oldfield B, Giles M, Paxinos G, McKinley M, Mendelsohn F. Chapter III localization of angiotensin receptors in the nervous system. Handb Chem Neuroanat (2000) 16:79-124. doi:10.1016/S0924-8196(00)80005-6

29. Allen AM, Zhuo J, Mendelsohn FA. Localization and function of angiotensin AT 1 receptors. Am J Hypertens (2000) 13(1):S31-8. doi:10.1016/ S0895-7061(99)00249-6

30. Ardaillou R. Angiotensin II receptors. J Am Soc Nephrol (1999) 10:S30-9.

31. Zambidis ET, Soon Park T, Yu W, Tam A, Levine M, Yuan X, et al. Expression of angiotensin-converting enzyme (CD143) identifies and regulates primitive hemangioblasts derived from human pluripotent stem cells. Blood (2008) 112(9):3601-14. doi:10.1182/blood-2008-03-144766

32. Hubert C, Savary K, Gasc JM, Corvol P. The hematopoietic system: a new niche for the renin-angiotensin system. Nat Clin Pract Cardiovasc Med (2006) 3(2):80-5. doi:10.1038/ncpcardio 0449

33. Juillerat-Jeanneret L, Celerier J, Bernasconi CC, Nguyen G, Wostl W, Maerki H, et al. Renin and angiotensinogen expression and functions in growth and apoptosis of human glioblastoma. Br J Cancer (2004) 90(5):1059-68. doi:10.1038/sj.bjc.6601646

34. Deshayes F, Nahmias C. Angiotensin receptors: a new role in cancer? Trends Endocrinol Metab (2005) 16(7):293-9. doi:10.1016/j.tem.2005.07.009

35. Bradshaw A, Wickremesekera A, Brasch HD, Chibnall AM, Davis PF, Tan ST, et al. Cancer stem cells in glioblastoma multiforme. Front Surg (2016) 3:21. doi:10.3389/fsurg.2016.00048

36. Tan EM, Chudakova DA, Davis PF, Brasch HD, Itinteang T, Tan ST. Characterisation of subpopulations of myeloid cells in infantile haemangioma. J Clin Pathol (2015) 68(7):571-4. doi:10.1136/jclinpath-2014-202846

37. Nguyen G, Delarue F, Burckle C, Bouzhir L, Giller T, Sraer JD. Pivotal role of the renin/prorenin receptor in angiotensin II production and cellular responses to renin. J Clin Invest (2002) 109(11):1417-27. doi:10.1172/JCI0214276

38. Dinh DT, Frauman AG, Johnston CI, Fabiani ME. Angiotensin receptors: distribution, signalling and function. Clin Sci (2001) 100(5):481-92. doi:10.1042/ cs1000481

39. Zhang W, Xu Y-Z, Liu B, Wu R, Yang Y-Y, Xiao X-Q, et al. Pioglitazone upregulates angiotensin converting enzyme 2 expression in insulin-sensitive tissues in rats with high-fat diet-induced nonalcoholic steatohepatitis. Sci World J (2014) 2014:7. doi:10.1155/2014/603409

40. LiX, Shams M, Zhu J, Khalig A, Wilkes M, Whittle M, et al. Cellular localization of AT1 receptor mRNA and protein in normal placenta and its reduced expression in intrauterine growth restriction. Angiotensin II stimulates the release of vasorelaxants. J Clin Invest (1998) 101(2):442. doi:10.1172/JCI119881

41. Chow L, Rezmann L, Imamura K, Wang L, Catt K, Tikellis C, et al. Functional angiotensin II type 2 receptors inhibit growth factor signaling in $\mathrm{LNCaP}$ and PC3 prostate cancer cell lines. Prostate (2008) 68(6):651-60. doi:10.1002/ pros. 20738

42. Bernstein KE, Martin BM, Edwards AS, Bernstein EA. Mouse angiotensin-converting enzyme is a protein composed of two homologous domains. J Biol Chem (1989) 264(20):11945-51.

43. Li C, Heidt DG, Dalerba P, Burant CF, Zhang L, Adsay V, et al. Identification of pancreatic cancer stem cells. Cancer Res (2007) 67(3):1030-7. doi:10.1158/0008-5472.CAN-06-2030

44. Eramo A, Lotti F, Sette G, Pilozzi E, Biffoni M, Di Virgilio A, et al. Identification and expansion of the tumorigenic lung cancer stem cell population. Cell Death Differ (2008) 15(3):504-14. doi:10.1038/sj.cdd.4402283
45. Collins AT, Berry PA, Hyde C, Stower MJ, Maitland NJ. Prospective identification of tumorigenic prostate cancer stem cells. Cancer Res (2005) 65(23):10946-51. doi:10.1158/0008-5472.CAN-05-2018

46. Ricci-Vitiani L, Fabrizi E, Palio E, De Maria R. Colon cancer stem cells. J Mol Med (Berl) (2009) 87(11):1097-104. doi:10.1007/s00109-009-0518-4

47. Prince M, Sivanandan R, Kaczorowski A, Wolf G, Kaplan M, Dalerba P, et al. Identification of a subpopulation of cells with cancer stem cell properties in head and neck squamous cell carcinoma. Proc Natl Acad Sci U S A (2007) 104(3):973-8. doi:10.1073/pnas.0610117104

48. Ma S, Chan KW, Hu L, Lee TKW, Wo JYH, Ng IOL, et al. Identification and characterization of tumorigenic liver cancer stem/progenitor cells. Gastroenterology (2007) 132(7):2542-56. doi:10.1053/j.gastro.2007.04.025

49. Singh SK, Hawkins C, Clarke ID, Squire JA, Bayani J, Hide T, et al. Identification of human brain tumour initiating cells. Nature (2004) 432(7015):396-401. doi:10.1038/nature 03128

50. Tan BT, ParkCY, Ailles LE, Weissman IL. The cancer stem cell hypothesis: a work in progress. Lab Invest (2006) 86(12):1203-7. doi:10.1038/labinvest.3700488

51. Herr D, Rodewald M, Fraser H, Hack G, Konrad R, Kreienberg R, et al. Potential role of rennin-angiotensin-system for tumor angiogenesis in receptor negative breast cancer. Gynecol Oncol (2008) 109(3):418-25. doi:10.1016/ j.ygyno.2008.02.019

52. Suganuma T, Ino K, Shibata K, Kajiyama H, Nagasaka T, Mizutani S, et al. Functional expression of the angiotensin II typel receptor in human ovarian carcinoma cells and its blockade therapy resulting in suppression of tumor invasion, angiogenesis, and peritoneal dissemination. Clin Cancer Res (2005) 11(7):2686-94. doi:10.1158/1078-0432.CCR-04-1946

53. George AJ, Thomas WG, Hannan RD. The renin-angiotensin system and cancer: old dog, new tricks. Nat Rev Cancer (2010) 10(11):745-59. doi:10.1038/ nrc2945

54. Ager EI, Neo J, Christophi C. The renin-angiotensin system and malignancy. Carcinogenesis (2008) 29(9):1675-84. doi:10.1093/carcin/bgn171

55. van der Knaap R, Siemes C, Coebergh JWW, van Duijn CM, Hofman A, Stricker BHC. Renin-angiotensin system inhibitors, angiotensin I-converting enzyme gene insertion/deletion polymorphism, and cancer. Cancer (2008) 112(4):748-57. doi:10.1002/cncr.23215

56. Lever AF, Hole DJ, Gillis CR, McCallum IR, McInnes GT, MacKinnon PL, et al. Do inhibitors of angiotensin-I-converting enzyme protect against risk of cancer? Lancet (1998) 352(9123):179-84. doi:10.1016/S0140-6736(98)03228-0

57. Lu S-J, Feng Q, Caballero S, Chen Y, Moore MA, Grant MB, et al. Generation of functional hemangioblasts from human embryonic stem cells. Nat Methods (2007) 4(6):501-9. doi:10.1038/nmeth1041

58. Mao J-M, Liu J, Guo G, Mao X-G, Li C-X. Glioblastoma vasculogenic mimicry: signaling pathways progression and potential anti-angiogenesis targets. Biomark Res (2015) 3:8. doi:10.1186/s40364-015-0034-3

Conflict of Interest Statement: The authors declare that the research was conducted in the absence of any commercial or financial relationships that could be construed as a potential conflict of interest. TI, PFD, and STT are inventors of the PCT patent application (No. PCT/NZ2015/050108) cancer diagnosis and therapy.

Copyright (c) 2016 Bradshaw, Wickremesekera, Brasch, Chibnall, Davis, Tan and Itinteang. This is an open-access article distributed under the terms of the Creative Commons Attribution License (CC BY). The use, distribution or reproduction in other forums is permitted, provided the original author(s) or licensor are credited and that the original publication in this journal is cited, in accordance with accepted academic practice. No use, distribution or reproduction is permitted which does not comply with these terms. 